\title{
Cultural Heritage and Obia
}

\author{
Givliana Bilotta $^{1 *}$, Rossella Nocera ${ }^{2}$, Pier Matteo Barone ${ }^{3}$ \\ ${ }^{1}$ NT\& ITA Department of Planning, University IUAV of Venice \\ Santa Croce 191, Tolentini 30135 Venice, ITALY \\ ${ }^{2}($ DiBT $)$ - Biosciences and Territory Department, University of Molise \\ Via Duca degli Abruzzi, 86039 Termoli (CB) Italy, ITALY \\ ${ }^{3}$ Archaeology and Classics Faculty, American University of Rome \\ Via Pietro Roselli, 400153 Rome, ITALY
}

\begin{abstract}
The historic centre of a town is its oldest and original core. It needs special protection in order to ensure the conservation of its historical, artistic and environmental heritage. In Italy, the definition of historic centres and the protection of their cultural heritage evolved in time, up to the current special attention for the historical aspects. The main threats to historical centres are real estate speculation and mass tourism. The purpose of this study is to catalog and monitor historic centers over time, in the context of urban planning. High-resolution satellite images and geographic information systems (GIS) offer new tools for urban planning and also for cultural heritage themes. "Real time" evaluation of urban structures, cartographic updating, monitoring of the progress of major works, with particular regard to cultural heritage, are made possible by the use of high-resolution images, which facilitate the identification of changes in urban and non-urban areas. The technique of Object Based Image Analysis (OBIA) has been used for image analysis and interpretation. OBIA allows a good interpretation of the scene captured by sensors thanks to classification-based segmentation and extraction of complete objects and their topological relations. This yields to a classification similar to the output of human photo-interpreter, but with a better reproducibility and homogeneity. In this paper we describe, through an application example, the potentiality and the difficulties of this technique and some results. The whole information obtained from segmented and categorized satellite images has been structured in a proper GIS, so that it can be overlaid with other environmental data. Information structuring and special metaheuristic analyses allow to study and monitor historic centers and cultural heritage. This methodology allows to identify the places at risk that need priority restoration; moreover it allows to keep track of changes that occurred over time.
\end{abstract}

Key-Words: - cultural heritage, historical centres, satellite images, monitoring, object base image analysis, GIS.

Received: December 23, 2020. Revised: April 20, 2021. Accepted: April 28, 2021. Published: May 5, 2021. 


\section{Introduction}

Cultural heritage is a system of assets which, due to their particular historical, cultural and aesthetic importance, are of public interest and represent the wealth of a place and its population.

The noun "heritage" refers to the assets that compose it, because of their artistic and historical value. It is the legacy of physical artifacts and intangible attributes inherited from past generations, and the existence of a regulation that concerns all things of value: the so-called cultural assets.

Cultural assets are that system of things that make up heritage, both culturally and economically. It is a complex monetary value, susceptible to extreme fluctuations and subject to infinite variables. When a company defines its art objects and legally protects them, it does a selection that aims to recognize the historical and aesthetic value of these objects that make up the heritage of the community. Cultural heritage is a dynamic and everexpanding system. It is part of continuous discoveries and acquisitions of data and materials (research in the fields of art history and architecture, archeology, archival and bibliographic documentation and social histories never stops), as well as artistic and expressive experiments of our times or of the past. In the " $60 \mathrm{~s}$, a specific study commission gave a definition of "cultural heritage" which is still valid: cultural heritage is a material evidence having the value of civilization.

Therefore, examples of civilization, history and culture are assets of historical and artistic interest, monuments, archaeological, archival, book and landscape-environmental assets.

They have a recognized artistic value and belong to culture and to the community, they are historical testimony and object of aesthetic education. For all these reasons they need enhancement and protection.

The assets that are part of the cultural heritage express not reproducible and unrepeatable values of the society they emanate from (they are "unicum", there are no replicas, nor is there another asset that have same formal, aesthetic and symbolic characteristics.

The assets can be movable (transportable) or immovable (permanently anchored to the place where they were built).

Italian law about cultural heritage (mainly Bottai law n.1089/1939) defines and classify several types of assets (Fig.1):

- Artistic and historical assets: all works and monuments, both movable and immovable, which have a recognized artistic value or a special historical significance;
- Architectural assets: all buildings, architectural ensembles and monuments. Therefore, real estate ehose artistic or historical value has been recognized;

- Archaeological assets: movable or immovable assets and testimonies from the past, brought to light through technical excavation or not yet found, but whose presence is ascertained in a given place;

- Historical centres. An urban and building complex where road system and its urban activities have never been interrupted;

- Book assets and libraries: these assets are usually within libraries, which collect the books, safeguard their integrity and make them accessible to the public. Libraries can be stateowned or dependent on local authorities, nonprofit organizations, monasteries or belonging to private property;

- Archival assets: these assets include both documents and archives, i.e. those public instructions intended for the conservation of public and private acts and documents that are of state competence;

- Museums. They are important institutions, capable of hosting and exhibiting a series of movable assets, which are kept, catalogued and exhibited to the public (museums can be public or private).

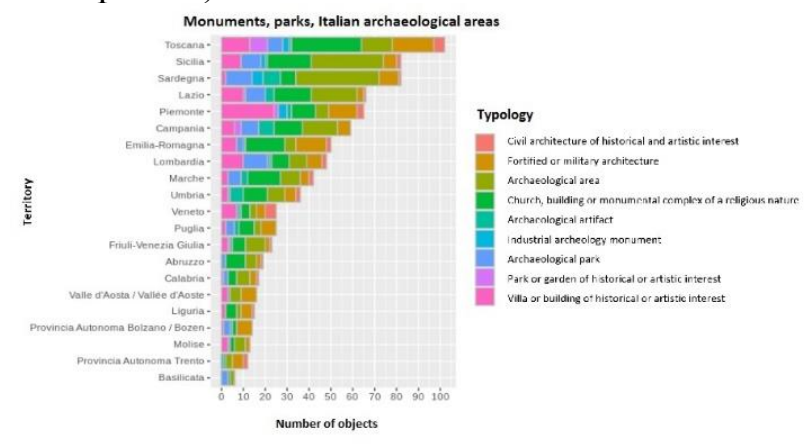

Fig.1 Monuments, parks, Italian archaeological areas (ISTAT, 2016)

Environmental assets, instead, are part of the cultural heritage of a country and are recognized as chorographic areas representative of a specific region, which constitute natural or man-made landscapes (those areas in which there are urban settlement structures which, due to their value, offer evidence of civilization). There are two main types of environmental assets:

- individual beauties, i.e. those that retain an uncommon intrinsic spontaneous value (parks, caves, natural bays, etc.) 
- the overall beauties of the whole, that is the natural forms or buildings that must be protected, as an integral part of a unitary complex of particular value.

It is not possible to protect what is unknown. A list of "things", "movable or immovable" is the basis of any protection initiative.

Already in the late Middle Ages the treasures kept in churches were inventoried; during the Renaissance the popes prepared lists of movable materials to stem the dispersion of antiquities and to control ownership of statues and paintings.

The need to protect heritage, therefore, is always accompanied by census initiatives: in 1773 "the Council of Ten" commissioned the scholar Anton Maria Zanetti to draw up a list of all the pictorial works kept in the city of Venice, also providing the formalization of the lists, to be delivered to the various administrators of these assets. Sine Pacca edict in 1820 , a written registry of assets becomes mandatory.

The Catalog can be a file, inventory, register or a database. Cataloging is a set of processes supported by historical-aesthetic analysis. A filing and cataloging campaign is therefore strictly connected with the principles of heritage protection. The examination of the inventories of the collections, whether they were private, public, belonging to churches or other entities, allows to document the history of the collections and of the individual pieces. These indispensable classifications, now almost entirely published and available for consultation by students and scholars, do not follow fixed models: in some cases the surveys are rich of and technical about the author; in other cases it happens that the compiler is stingy with information, or indulges in aesthetic judgments or attributions of paternity that confuse the researcher.

In the Bottai Law of 1939, the need for "descriptive lists" for public and private assets was invoked, to be systematically updated. The lists were an easy means to verify existing assets for administrative purposes. The cataloging implies an identification and recognition of the historical or artistic value of the assets.

The same methodology is valid for Historical centres, mentioned above as urban and building whose residential viability and urban function have never been interrupted. Also the process of enlargement outside the ancient walls have never altered their view. But this definition changed.

The historic centre of town or an inhabited centre is now that part of the municipal territory of the oldest core subject to protection in order to ensure the conservation of historical, artistic, environmental evidence.

The attention and the urban definition of the historic center was born during the twentieth century when we began to think first of the restructuring and then of the preservation of the old part of the city. In Italy there are thousands of historical centers, of various shapes and sizes. Many of these have a high architectural value both for their whole and for the architectural works they contain. A few years ago, according to a survey of the Italian National Institute of Statistics (ISTAT) the Italian historical centers of various origins, Etruscan, Greek, Roman, medieval, Renaissance, Baroque, and from the Fascist era, number 22,000 [1].

After the war, with the awareness of the need for a recovery of the values and of the Italian historical tradition, with the movements of "architectural Neorealism" and Neoliberty, it was thought about the safeguarding and conservation of the historical built environment. Various attempts have been made to develop efficient recovery rules.

In recent decades, progress has been made with the development of recovery concepts and with urban planning definitions such as that of historicity, which has expanded to mean the cultural values of a city, which cannot be limited to a specific central area. These expand in the territory where ancient buildings similar to those ones of the city are found and they must be safeguarded. Therefore, not only the most illustrious buildings, the valuable architectural detail, the works of art and the spaces of public life (municipal buildings, squares, churches), but whole the historical built environment, which goes beyond even the same borders of the city of the past, and has precise morphological and architectural connotations. Within the urban planning, which was implemented with the general regulatory plans (PRG) that today are Municipal Urban Plans (PUC), the historic centers correspond to the homogeneous territorial area identified by the letter "A". "It includes the parts of the territory with urban agglomerations historical, artistic and of particular environmental value or portions of them, including the surrounding areas, which can be considered an integral part of the agglomerations themselves." (Article 2, paragraph 1, of the interministerial decree no. 1444 of 2 April 1968).

In Italy there are many little-known centers of territories (called "minor historical centers") that can be considered the territorial "armor" that outlines their identity. They are the concrete evidence about cultural complexity, settlement 
stratifications and social changes. The historic centers of small towns are found to be fundamental points, central elements of each territorial system as they contain the material and immaterial experiences and the cultural essence of each community. The places of living and producing, the symbols of political and religious power, the road system give life to a harmonious whole. This is the result of stratifications attributable to different economic, social, political-institutional matrices that must be preserved. Historic centers have different qualities, but they are all full of traces of the past, places history and communities who live or lived there.

Unlike the historical urban areas in which the city-territory relations have been mediated and then consumed by successive expansions and by the strong functional restructuring, the minor historical centers largely maintain a strong environmental, morphological and landscape relationship with surrounding territory and its core. However, they have also a significant economic, settlement and infrastructural value because, together with the local networks, they still are a widespread and articulated infrastructural resource to support enjoyment of natural values, recovery of historical, innovative or economic activities. Therefore, in Italy, minor historical centers are a fixed capital available to the community, largely unused or underused.

The reasons for marginality and underutilization are manifold. These undoubtedly include the contrasting dynamics of socio-economic, urban and metropolitan development of the last sixty years, the prevalence of standardized models of consumption (supply and demand), often in contrast with historical and cultural traditions; but also, traditions, cultures, economies that did not have the strength to re-propose themselves within the new reference models and in the processes of cultural formation that were at the base. The abandonment and aging of the population can be considered as the main factors of a process of obsolescence that still affect small historic centers. Also nowadays there is a gradual process of abandonment, because any transformation and adaption of settlement to the need of new generation have been adopted.

We must distinguish the historic centers of the cities from the small provincial villages, which have different historical and morphological characteristics, and take different risks.

For the city centres there are risks linked to speculation, gentrification, mass tourism: from the transformation of public spaces, which become ground for unnatural furnishing arrangements and for a serial catering and recreational offer, to that of construction, which it loses its historical-artistic and typological characteristics due to the search for home comfort appropriate to the times, for the real estate subdivisions, for the proliferation of B \& Bs and for the concentrated introduction of commercial establishments, often of enormous size. Each new activity is now subject to specific rules, which provide for the introduction of various elements and changes, sometimes incompatible with the identity of the historical building. Exceptions could also be introduced to reconcile specific requests with respect for the characteristics of historic buildings, even if they are not protected like monuments.

For small villages, there is a risk associated with depopulation: the absence of building maintenance due to the low population and widespread poverty of the few residents is the premise of material degradation. Where small towns are tourist destinations of great appeal, the risk is instead that of transformation into historical fakes with the revival of typical lost elements, the standardization of the image and the cancellation of historical passages [2].

At the beginning of 2018, some scholars, urban planners with their cultural associations undertook to relaunch the theme of the conservation of historic centers. They felt obliged to do so having seen and known that in Rome it was possible to replace the villas of the early twentieth century with ordinary building speculation; that in Florence a variant to the General Urban Plan was being approved, aimed at canceling the restoration and allowing the building renovation even of restricted buildings. News that followed the alarming worsening of the depopulation of Venice. They therefore decided to promote a conference on distortions in the use of the housing heritage of historic centers, especially those of cities of art, affected by a real exodus of residents, massively replaced by tourists and tourism-related activities (while small municipalities of the inland areas of the South, are bled by emigration).

The conference, entitled "The right to the historic city", was held in Rome in November 2018, fifty years after Henri Lefebvre's book on the right to the city. It was preceded by study seminars, to recall and discuss the events that gave rise to the culture of conservation and recovery in Italy in the second half of the last century. Starting with Antonio Cederna, the first to understand (just read the introduction to "I vandali in casa", from 1954) that the historic city is a unitary complex, not an assortment of smaller buildings and more or less important architectures. Cederna's thought was profoundly innovative when the belief still prevailed that protection should be 
limited to buildings of monumental importance (churches, palaces, etc.) while the basic building fabric was available for demolition and replacement for hygiene reasons, of traffic, of aesthetics. In 1960, four years after the "Vandali", the "Gubbio Charter" (approved at the first meeting of ANCSA National Association of Historic Artistic Centers) declares the intangible unity of historic centers: the historical centers are not only containers of monuments but are themselves a monument.

The Gubbio Charter was taken up by the socalled "bridge law" which introduced, among the contents of the master plan, the protection of the landscape and of historical and monumental complexes environmental and archaeological (for the first time the word landscape appears in an ordinary law). Provisional solutions were envisaged, but certainly effects that have largely allowed Italy, before and better than other European countries, to save its historic centers, putting a stop to the very serious alterations, if not the actual destruction that took place in the first post-war period. (in Milan, for example).

From protection to recovery. The first was the plan of the historic center of Bologna in the early seventies known all over the world, strongly desired by the councilor Pierluigi Cervellati to build social housing through the restoration of the historic housing heritage. These were the best years of Italian town planning. Mind you, then, as always, bad governance and devastating speculative interests prevailed in most of Italy, but there was also a diffuse hope that things could change following the example of Bologna and other important experiences developed in the following decades (to remain in the field of conservation of historic centers: in Taranto, Venzone, Rome, Como, Brescia, Venice, Palermo, Naples).

The world changed with the 1980s. Gradually, conservation and recovery were set aside, then reneged. The most painful events take place in Bologna and Emilia Romagna where Mibact and the Region have established that the reconstruction after the 2012 earthquake was going well where it was, not as it was. In addition, with the urban planning law of Emilia Romagna approved in December 2017, a much discussed and opposed urban planning law, for example, by great urban planners such as Edoardo Salzano on his Eddyburg website [3]. The conference did not stop at the denunciation, but proposed a bill for the protection of historic centers. It is based on the direct intervention of the State, with the declaration of historic centers as "overall cultural assets", with a ban on demolition and reconstruction, and transformation. A series of "principles" of good governance of the territory are added to the state competences, which must be implemented by regional legislation with the request for a direct and extraordinary intervention by the State as in cases of serious natural disasters [4].

Within the overall framework outlined so far, is well understood as the basis of everything is a cataloging and monitoring of historic centres in the context of urban planning.

High-resolution satellite images offer new tools for urban planning. The "real time" evaluation of urban structures, cartographic updating, monitoring of the progress of major works, are possible thanks to the use of high-resolution images. From the infrared multispectral images, it is possible, in addition to changes in the presence and shape of the structures on the territory, to identify the heat sources (industries, anomalous sources), the degree of pollution of particularly complex urban and nonurban areas.

The following activities can be carried out:

- Valuation of cadastral real estate properties

- Evaluation of building abuses

- Updating of maps

- Emergency planning

- Territorial planning and management of the General Regulatory Plans

- Water resources management

One of the most effective tools in the field of remote sensing is the Object Based Image Analysis techniques

The main advantage of automatic object-based analysis is the reproducibility of the photointerpretation process so far entrusted to the human interpreter, certainly not reachable for refinement and experience but impossible to make homogeneous over time and therefore comparable. The textural signature of the urban structure, obtained with the accurate attribution of the characteristics to the membership functions that structure the class hierarchy, can be identified in a much shorter time and with lower costs. This availability and the accessibility of satellite datasets and at short time distances mean that monitoring can be carried out even at intervals of a few months, making control of the territory effective and effective. The limit of the pixel based analysis, even if it is carried out automatically, is in making the machine recognize only low semantic level information such as reflectance, that is the amount of energy the pixel emits, while the context does not take on any importance. In the object based analysis, on the other hand, the semantic rank rises. Spatial relationship rules, statistics and topological information are added. In summary, the context is 
estabilished. Concepts of Mathematical Morphology [5-7] guide the recognition applied to image analysis; it follows the principles of Fuzzy Logic [89]; moreover, every rule can take on the appropriate weight, and the context becomes as important as in the human photo-interpretation.

\subsection{Operative phases}

The work we present here proceeds according to the following steps:

1) segmentation and classification of hamlets through object-based analysis of satellite image

2) Point of Interest are identified and surveyed with geomatics techniques, and relevant data are acquired in order to build characteristic information sheets for each asset.

3) A GIS has been implemented structuring data about:

- segmented area;

- points of interest previously surveyed;

- relevant elements in the study area (roads, urban centres, etc.);

- parameters such as economic attractiveness, risk areas, etc.

Special Meta-heuristic analysis have been performed to identify and visualize over time risk area for each asset.

\subsection{Study Area}

The knowledge of urban transformation phenomena is expressed through land use maps for the control of urban transformation.

The study area is located in the Municipality of Melito di Porto Salvo (Province of Reggio Calabria, South Italy), a coastal town in the extreme south of the Italian peninsula that extends over just over 35 square $\mathrm{km}$. The altitude varies between 0 and 780 meters above sea level.

Principal aim of this study is define a methodology that allow to realise land use maps for the government of the urban territory using high resolution satellite datasets integrated with other data such as orthophotos, UAV surveys, Lidar data, cartography, etc. and software for object-based analysis of remote sensing images.

Until recently, the spatial resolution of the images offered by Earth Observation satellites was not sufficient to provide detailed topographical characteristics such as shape and structure, and this was strongly felt in applications such as that of analysis and monitoring of urban environment.

Therefore, analysis tools are necessary to use also structural and form information contained in the images. Some of these tools are used for long time in other fields such as medical image processing.

The information that comes from the satellite sensor is only the quantity of electromagnetic energy at different wavelengths, information generally irrelevant to the research problem. In addition to this, all spectral processing methods are based on the assumption that similar objects in the real world are also similar in the world of spectral information representation.

In reality there is no direct relationship between observed spectral behavior and thematic belonging. In fact, there are different spectral responses for the same material or the same spectral responses for different materials.

Furthermore, some categories of thematic information, i.e., some semantic levels, do not appeal to notions relating to the type of materials that are on the ground. In fact, in the spectral approach the spatial context of the information cannot be described in a formalized manner.

The most common way to raise the semantic level of information is human visual interpretation, in which the structure and spatial arrangement of objects play an important role in shape recognition and image classification. This is also the case with object-based techniques.

\subsection{Multi-resolution segmentation}

With the applied software, the pixels of the original image are aggregated in a series of successive steps until the created polygons have characteristics corresponding to those desired. We tend to minimize the spectral heterogeneity of each polygon derived from the digital number $(\mathrm{DN})$ values of the included pixels on the basis of the geometric heterogeneity dependent on the shape of the polygons created.

If the segmentation process tended only to the minimization of the spectral heterogeneity, the more fragmented polygons the higher the geometric resolution of the image would be generated. The polygons created must also tend to minimize the geometric heterogeneity value, defined in turn by two form factors: the fractal factor, which depends on the complexity of the perimeter of the polygon with respect to its extension, and the compactness factor, which depends on the ratio dimensional axis of the polygon. Setting the scale factor allows to calibrate polygons size; its definition is linked to the reference scale of the cartography that the user want to obtain.

The segmentation process with the software eCognition is multi-resolution: by decreasing the scale factor the generated polygons become smaller 
and smaller because the internal spectral variability must be lower, and vice versa by increasing the scaling factor.

A peculiarity of the multiresolution is the interconnection existing between polygons of the different segmentation hierarchical levels.

The aim of this paper is to analyze land use/land cover and settlements not only for land use planning but also for Cultural Heritage and for monitoring historic centers and assets. From this point of view it would be useful to use a technique of analysis of remotely sensed data that allows to preserve identified attributes for the entities, such as shape and spatial relationship, that are important for our purpose.

OBIA, integrated with metaheuristic analysis, is a very useful tool and it allow to obtain prediction models about risk areas and entities. OBIA, with automatic or semi-automatic analysis, can be applied to identify and monitor historical centers and cultural heritage, obtaining vector objects that will be structured in a geographic information system (GIS) with their "inherited" attributes. There will be no overlapping errors because objects are extracted directly from same images to wich they overlap. It is also possible to use cadastral vector layer to guide the segmentation, so the derived objects "inherit" also cadastral attributes.

OBIA gave very good and fast results in the Global Land Cover 2000 (GLC 2000) population, obtaining higher accuracy - in one tenth of the time than the Corine Land Cover (CLC) of the 90s, despite the fact that GLC 2000 was global and therefore not only European like CLC.

\section{Problem Setting}

This paper refers to a study started a long time ago (2004) concerning the creation of a platform for the analysis and study of urban centers both from an urban planning point of view and for the implementation of maintenance interventions for risk mitigation, and the consequent possible destination and optimization of funds for the safeguarding of the present cultural heritage.

The use of Geographic Information Systems (GIS) is now indispensable also to support monitoring and processing of decision making for Culturtal Heritage. By capturing the salient aspects of the transformations that have taken place, it become a useful decision support systems. This need is so important that over time it became the subject of specific international projects.
The application was carried out with the use of:

- remote sensing software: ERMapper, ERDAS and eCognition, ENVI software (for the wide interoperability it presents).

- GIS software: Mapinfo and Autodesk Map and Qgis

Taking into account precisely how methodologies and technologies evolve over time.

The goal is classification of multispectral images with the two pixel-based and object-based classification techniques, with final classification based on a nomenclature system in nine classes on three or four thematic levels consistent with the European Corine Land nomenclature system Cover born in the 90s, and the subsequential use of GIS to implement data and generate spatial map of cultural heritage and places with priority need of restoration.

By way of example, we report procedures performed in the early stages of this study for the realization of the DTM.

When this research began, it was not easy to obtain a Digital Terrain Model. It was necessary to start from 3D files of contour lines in DXF format and manage them with several software. Different files format causes interoperability problems very oft.

Furthermore, since there was no Regional Technical Map in Calabria at the time, it was necessary to rely on the level curves of the municipal aerial photogrammetry which was limited, in fact, to the municipal area only. The images in Fig. 2 are related to these elaborations. The anomaly visible in the DTM was due to the "virtual" completion of the contour lines which actually stopped abruptly at the municipal limit.

The basic cartographic documentation was the municipal aerial photogrammetry with restitution in 1999 following a 1998 flight. Also in 1998 were the aerial shots for the production of color orthophotos in 1: 10,000 scale (IT2000 of the CGR). We had chosen the dxf file of the aerial photogrammetry in scale 1: 10.000 , from which we extracted the contour lines every 10 meters and 50 meters in two layers. Then we georeferenced in the representation Gauss Boaga fuse East, Datum Roma 40, and corrected the errors found in the dimensions by editing the 3D polylines of the curves in the dxf, returning only the elevation point by point to the correct value and keeping the other dimensions.

From the correct curves we created in ER Mapper a DTM (Digital Terrain Model) with the procedure of the minimum curvature, grid of $10 \times 10$ meters. 
For the first remote sensing image analysis from space we had taken into consideration a series of Landsat 7 images (the main instrument on board Landsat 7 is the Enhanced Thematic Mapper Plus, ETM+), provided to ESA by Eurimage like all Landsat images

Initially the panchromatic and multispectral bands of Landsat 7 were georeferenced on the basis of the mosaic of orthophotos.

In figure 2 are the boundaries of the municipality (red line) superimposed on the multispectral Landsat 7 in true colors (321) and the 3D display of the DTM. At the top center the DTM alone and at the bottom in 3D along with selected subsets of both images.

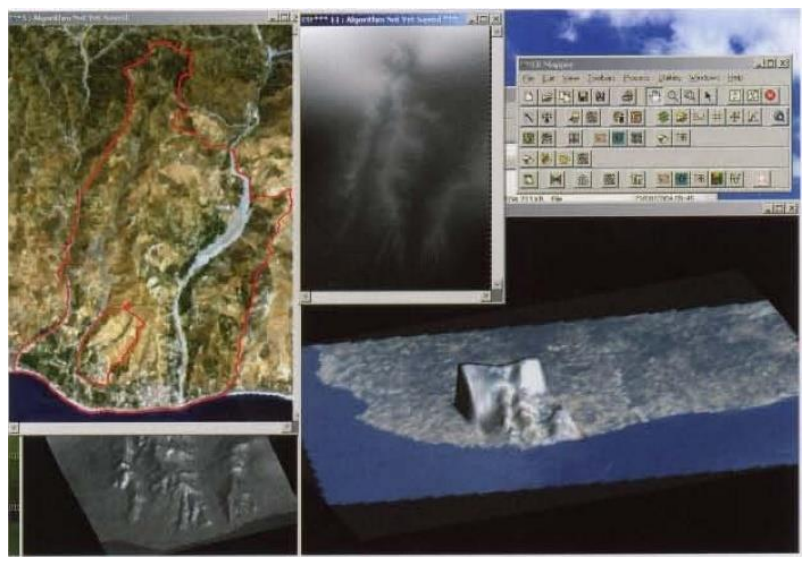

Fig.2 Landsat 7 image and 3D visualization of the DTM obtained from aerial photogrammetry. The Landsat 7 image is owned by the European Space Agency.

The anomaly of the DTM, very evident in the 3D visualization, was resolved with a subset of the municipal area only, in ERDAS with a dxf file with the municipal limits (transformed into shapefile with Mapinfo's Universal Translator) through the creation of a AOI (Area Of Interest). The same procedure was applied to the Landsat image and to the mosaic orthophotos.

We then performed a supervised classification of the Landsat subset from 1984.

As known, once the methodologies used in the first years of this study have been presented, it is good to observe how today the technologies for producing DTM and DEM have changed considerably and therefore can be produced in different ways. As an example, a DEM of the same area built by Lidar is shown (fig. 3). Obviously, the new procedures are very easy and quick.
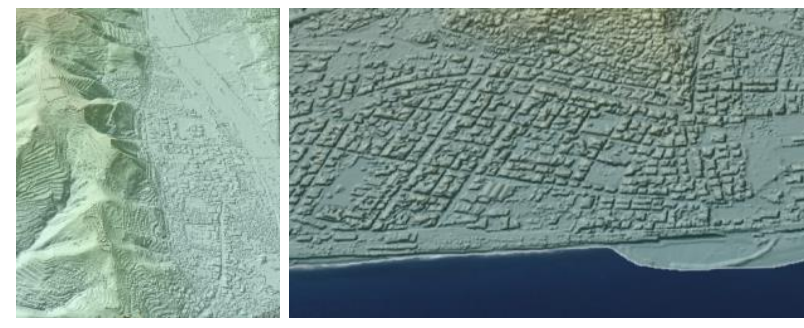

Fig.3 DEM built by Lidar.

\subsection{Processing with eCognition}

With eCognition [10] version 3.0 (then by the German Definiens Imaging $\mathrm{GmbH}$, now produced in the latest versions by the U.S. Company Trimble), the first processing was performed on the multispectral Landsat 7 image dated 13.07.2001.

Fig.4 shows eCognition procedures.

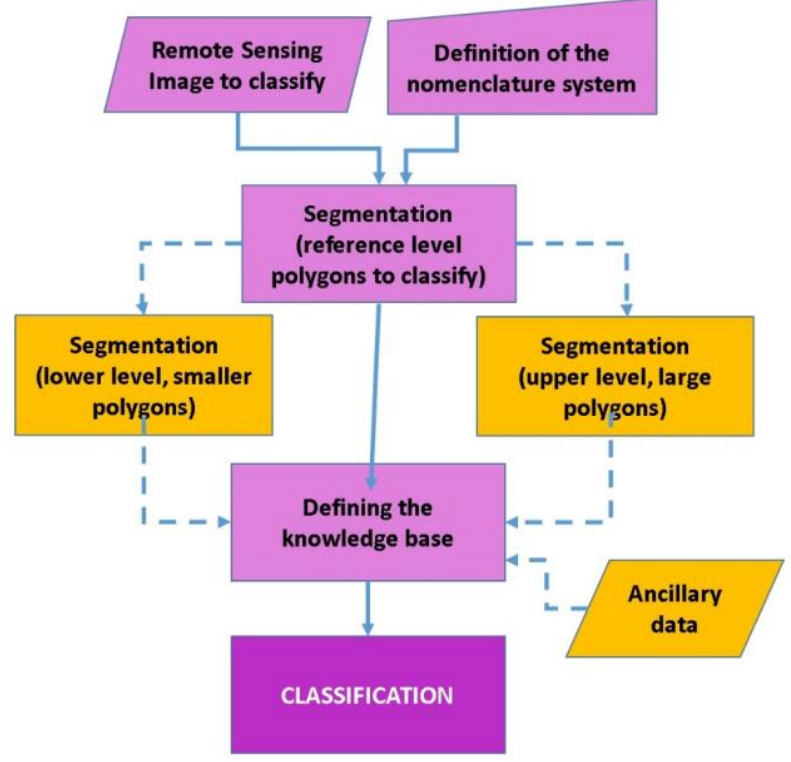

Fig.4 eCognition procedures diagram: purple steps are mandatory, yellow steps (dashed arrows) are optional.

This technique starts with one-pixel objects: in fact, the segmentation is a bottom-up merging technique, which produces smaller and smaller image objects merged into larger objects. During the clustering process, the optimization procedure reduces the weighted heterogeneity (arbitrary) of the obtained image objects. At each step, adjacent image objects are merged to represent the smallest growth of the chosen heterogeneity. The described process stops when this growth exceeds the threshold we defined with the scaling parameter. Thus, multiresolution segmentation is an optimization procedure that acts locally. We obtain the color (or spectral) heterogeneity by summing, in each level, the standard deviations of the weighted 
spectral values with the weights we have assigned to each level.

If we only tried to minimize spectral heterogeneity, however, we would obtain image objects or branching segments with a fractal-shaped edge, which would have a heavy effect in structured data, such as in radar data.

Therefore, it is useful for the spectral heterogeneity criterion to be mixed with the spatial heterogeneity criterion to obtain elongated or compact shapes. The spatial heterogeneity is the deviation from a compact size, identified by the ratio of the edge length to the square root of the number of pixels composing the image object.

The compactness factor therefore depends on the ratio of the dimensions of the axes of the polygon and is lower the longer the edge.

The segmentation algorithm merges contiguous polygons starting from each pixel in the image until the heterogeneity variation between the two previous polygons and then until the new polygon exceeds the user-defined scaling factor, i.e. the threshold value. As long as the change in heterogeneity does not exceed the defined threshold, the merging is actually implemented; when the change exceeds the threshold, the two polygons remain separate.

In addition, the change in shape heterogeneity, caused by the merger, is evaluated by calculating the change between after and before the merger. This involves computational methods for compactness and smoothness.

Multiresolution segmentation creates levels with the parameters given in the table, which takes into account the characteristics of the dataset.

If we were looking for elongated shapes, such as in the case of waterways or roads, we would have to both assign a very high value (e.g., 0.9$)$ to the shape factor and, consequently, a very low value $(0.1)$ to the color content (which, recall, is the radiometric content of the pixel), and we would also have to assign a minimum factor (e.g., 0.1) to compactness to identify objects that have strong perimeter development. Choosing instead a higher compactness factor would identify, for example, building roofs. By indicating a high scale factor, we will obtain an image that is not excessively fragmented.

In this application bands used were five; Blue, Green, Red, NIR (Near lnfrared), MIR) (Medium Infrared). The Thermal Infrared and Far Infrared (FIR) bands, i.e. band six and band seven, have been removed, applying a different display (with the Layer fixing function) after a stretch of the histogram (Equalizing: Histogram). The "three layer mix" setting has assigned Red to band E, leaving Green to 2 and imposing Blue to band 3 .

Multiresolution Segmentation was used to create a first level of image objects that group the pixels, setting the weight to be attributed to band 1 to zero; the other parameters chosen, namely the scale (10) and the homogeneity criteria such as color $(0.8)$ and shape (0.2), and of the latter smoothness (0.6) and compactness (0.4), are illustrated in figure 5.

To obtain a basic knowledge by means of the Class Hierarchy, after opening the Open Class Hierarchy dialog box, the four classes have been defined: Impervious surface, Water. Agriculture and Rural.

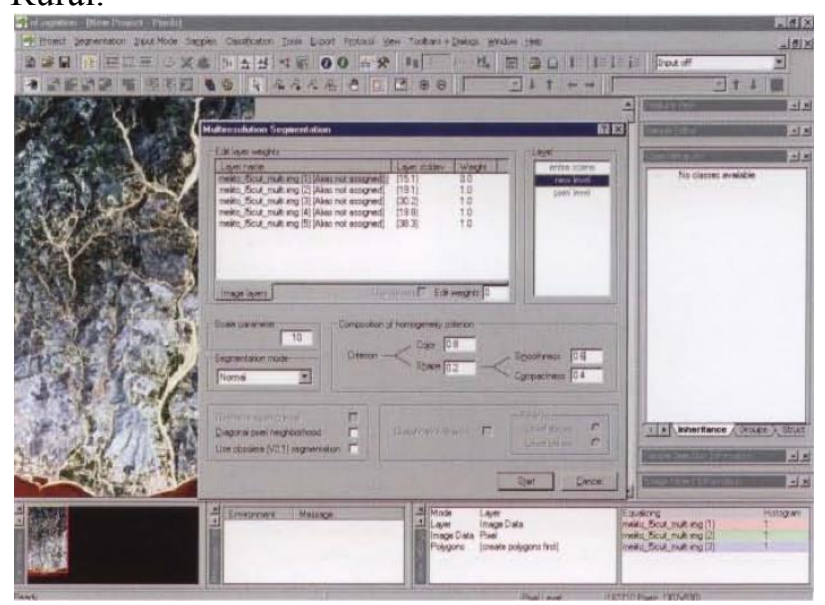

Fig.5 Setting of Multiresolution segmentation.

Advantages and disadvantages of Aerial Photo Interpretation (API), Pixel Based Analysis and OBIA are summarized in Fig. 6.

It seems useful to make some considerations about segmentation.

As known, there are several segmentation techniques implemented by different software (ENVI and ERDAS are the most important and used commercial software) that mainly apply edge-based algorithms. The advantage of OBIA is that ENVI (once by ITT, now by Harris Geospatial) segments the image after classification (thus losing some of the most important potentialities of a classification based on the created objects) and the segmentation algorithm used is edge-based (in the segmentation an edge-filter is applied to the image, pixels are classified as edge or non-edge, and pixels that are not separated by an edge are allocated to the same category), which requires the scale level as the only input parameter, so the level of segmentation created is a function of the scale level; while ERDAS Imagine (once by Leica Geosystems, now by Hexagon), on the other hand, in the versions released in recent years, segments for classification purposes but based mainly on the radiometric values 
of the pixel, without therefore taking into account the shape of the objects to be obtained (except in the most recent versions, with FLS - Fast Level Set Segmentation) nor the relationships between them. So, the advantage of the segmentation operated in this study is in obtaining at different levels (and different resolutions) interconnected image objects able to maintain their own attributes also geometric and their relationships.

This approach allows to divide (segment) the image into "groups" of homogeneous pixels (objects). OBIA, therefore, first segments the image and then classifies the objects.

Advantages:

- Good for high spatial resolution data.

- Represents the hierarchical scale of real-world multiscale ecosystems.

The second step in the process is the actual classification. All algorithms developed for pixelbased approaches can also be applied to polygons generated by segmentation.

We use objects:

- because they are more meaningful to the user;

- because they are statically driven;

- they are directly usable in GIS.

Classification is based not only on the spectral characteristics of the image, but also on shape, texture, context, and relationships with other objects, and enhances the high information content of the geometric component of remote sensing images. For this reason they are increasingly useful for Cultural Heritage.

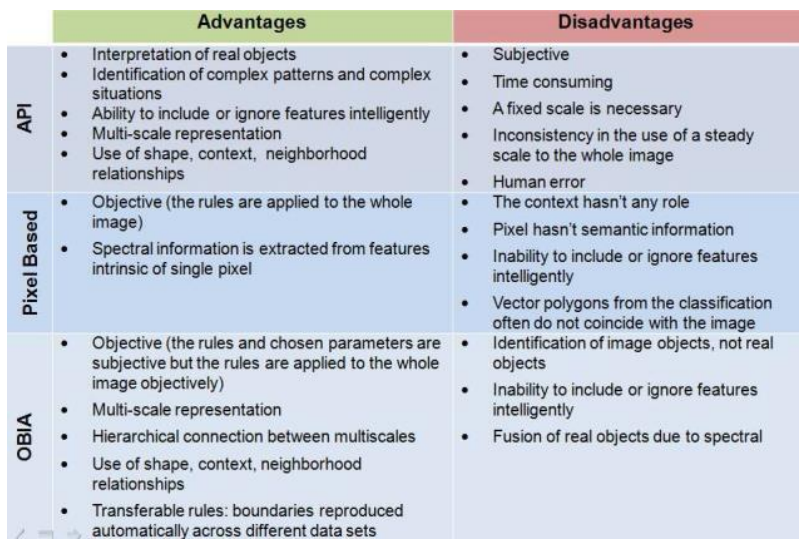

Fig.6 Advantages and disadvantages of Aerial Photo Interpretation (API), Pixel Based Analysis and OBIA.

\subsection{Classification of the Landsat dataset}

The eCognition software offers two different classifiers: Nearest Neighbor and Membership
Function. Here the Nearest Neighbor has been applied.

Nearest Neighbor classification of sample objects in eCognition is similar to supervised classifications in traditional image analysis software.

In this phase, to make it easier to identify image objects, it is necessary to change the view from "object mean" to "pixel" and activate the outlines in the View Settings, and then change the Layer mixing by attributing red to band 3 , green to near infrared and blue to medium infrared, thus obtaining a 543 representation.

The objects representing agricultural areas are thus intense green, waterproof objects appear in purple and violet and are characterized by a high degree of structure. Objects in the water are dark but do not blend in with objects in the shadow caused by mountainous terrain. All remaining objects represent rural areas, ie land cover with very varied spectral information; rural is therefore a heterogeneous motto class, but eCognition's Nearest Neighbor classification can handle such heterogeneities. Once the Sample Editor has been opened, the chosen samples have been selected: the dialog box displays five patterns for the characteristic values. The characteristics are the average values for each channel. Therefore, the feature space displayed in the Sample Editor is identical to the Nearest Neighbor standard space.

After selecting the test areas (TrainingTest Areas - TTA) for each class, the values of the characteristic of the reference object are displayed by the additional marks in the histograms. Starting a classification without class-related features, the first classification was obtained.

Turning off the contours it becomes clear that further improvement is needed (Fig. 7). There are in fact objects that are not assigned to classes and there is a number of objects classified incorrectly, particularly objects classified as agriculture in the upper left part of the image. In addition, too many objects are classified as waterproof surfaces. These inaccuracies will have to be corrected with iterative steps. 


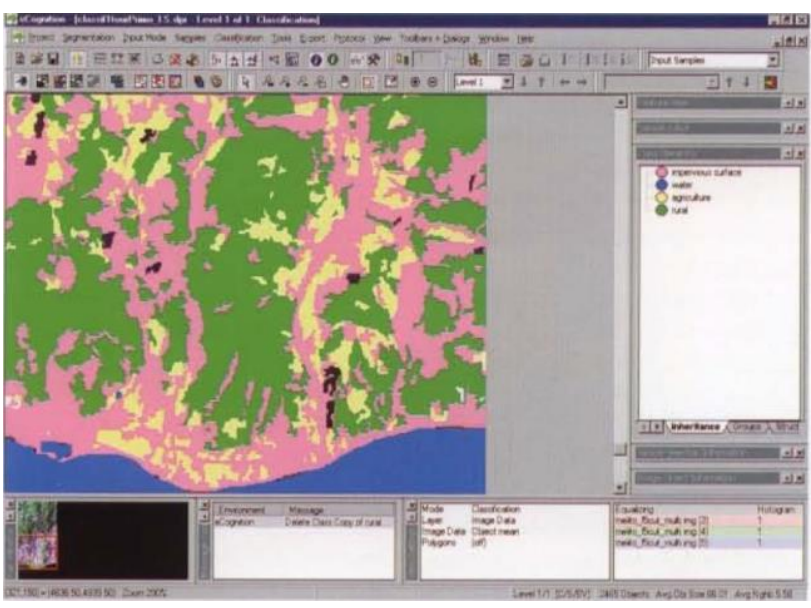

Fig.7: Landsat data classification in eCognition.

A segmentation of the lkonos dataset was carried out, choosing the scene relating to the west area because it was less affected by problems of shadows due to orography (Fig. 8).

A peculiarity of the territory in question is the presence of dry rivers for most of the year, so it is not easy to define a watercourse. It has also been seen that in the first Landsat classification the riverbed is confused with the urban, falling into the category of the Impervious.

Since the studied territory is also hilly, the use of a DTM could allow to discriminate the riverbed from the surrounding territory (with regard to the altitude) and from the Impervious.

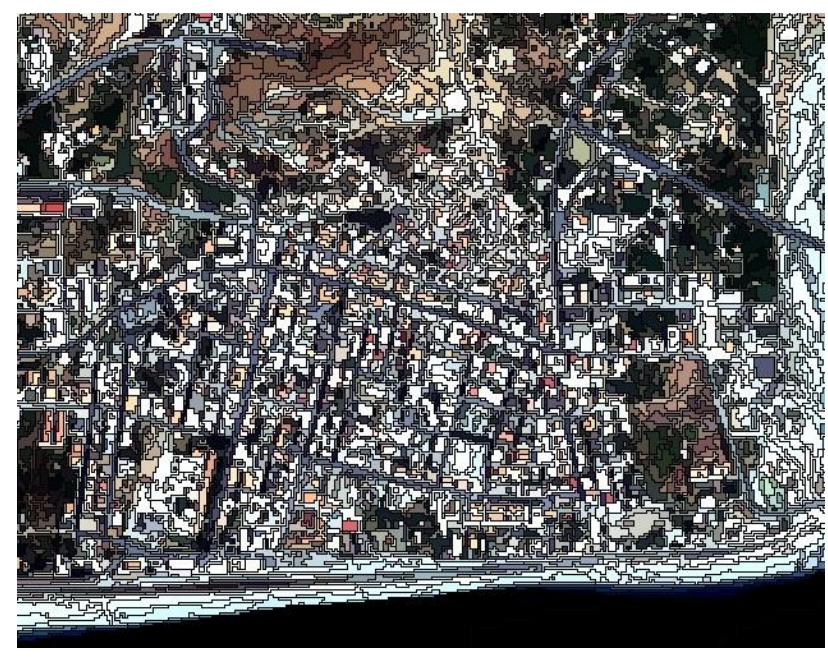

Fig.8: Segmentation in eCognition of the Ikonos data.

With the help of a panchromatic dataset (not present here), four levels of segmentation can then be created (Table 1).
Table 1: Segmentation settings

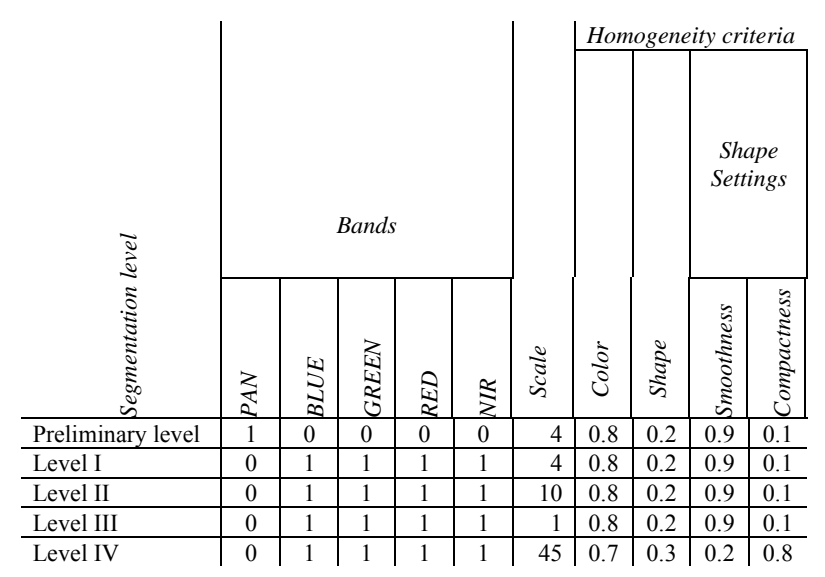

The preliminary level of segmentation to operate only on the eventual Ikonos pan dataset, is used to have objects at the maximum possible resolution. Level 1 is used to identify the base classes; Level 2 must be classified in more detail also on the basis of relations with the sub-level; 4 is used to classify large areas based on the density of the urban area in the sub-levels; finally, 3 exploits the relationships of all 3 levels described above to obtain the final, refined and correct classification.

It thus becomes possible to prepare a hierarchy of classes structured on the basis of the nomenclature indicated above, on four levels respectively with $4,12,18$ and 23 classes.

In illustrating the difficulties that can be encountered in the application of satellite data analysis techniques, it was intended to document the possibility of obtaining, with the object-based approach, a discrimination of the elements relating to the urban and its evolution in a more detailed and articulated than with the traditional pixel-based technique.

With regard to the structural approach [11-13], it was necessary to limit ourselves to a first classification and to the statement of the characteristics of the subsequent application. The continuation of this work should also lead to the creation of a confusion matrix for the evaluation of the classification obtained. The next step is therefore to deepen the analysis on the small urban center chosen to complete the evolutionary picture in the last twenty years and to extract a methodology to be applied to other territorial realities.

The preparation time for a good classification using the object-based approach was quite long, especially in the analysis and verification of the identification parameters. Once a classification procedure applicable with a fairly wide range of input data has been set up, it becomes possible to 
achieve great advantages both for the strong reduction of classification and control times and costs, for the homogeneity of evaluation. Very important the reproducibility with respect to a manual classification, both for the direct realization of a vector type result that can be immediately integrated into the GIS, already equipped with its own attributes.

Useful turns out, for the purposes of application in an integrated system for monitoring of urban changes, the ability of this software to segment the study area also on the basis of vector elements and, in this case, of the cadastral division of the property. This has an immediate reflection in the possibility of immediately preparing acts, such as orders, decrees and other provisions, both for the protection of properties and territories and to lay a basis also for the prosecution and repression of crimes.

With OBIA it is also possible to carry out further studies useful for the monitoring and updating of sector information, in addition to land use [14-17], illegal landfills [18], asbestos coverage [19], riverbeds, map updates [20-21], and environmental pollution. Other important aspects include assessing damage to vegetation and estimating $\mathrm{CO} 2$ emissions due to forest fires [22].

\section{GIS}

Geographic information systems (GIS) are nowadays essential tools to afford problems linked to management of cultural heritage, specifically architectural and landscape heritage, historical and artistic heritage, archaeological heritage, protection and enhancement.

Studies and research activities about these sectors are all the more effective if they are set up according to a dynamic process, which embraces the global dimension of the context. As known, GIS allow to address the management strategies of Cultural Heritage in an effective and innovative way in the context of territorial planning.

Regional historical centre map is very important in order to catalogue and monitor historic centres in the context of urban planning. "Real-time" evaluation of urban structures, cartographic updating and monitoring of the progress of major works, are increasingly necessary for an excellent service.

Several cartographic databases are therefore indispensable to share risk knowledge.

The implanted GIS thus created is also available for all citizens as a tool for disseminating geographic information that allows the management of the cartographic research for Cultural Heritage purposes.

It is, therefore, clear that mapping of areas is extremely useful to track and predict restoration solution, helping local authorities to establish where the resources have to be destined to prevent damage relating the Cultural Heritage.

For this purpose, in this work, we describe a methodology to define spatial prediction based on metaheuritics.

This methodology avoids the fast convergence, and helps the integrated algorithm to make better use of the search space [22].

The designed system uses, as input, seven different parameters (to establish areas at risk) related to climate, vegetation, topography, human activities and Cultural heritage information. We used several data to create final hazard maps:

- topographic maps

- geological map

- classified maps from remote sensing

- segmented maps from remote sensing

- land use

- landslide

- flood events occurred in the area

- NDVI

- Cultural Heritage info

All these data (that can be updated) have been suitable structured in a GIS with QGIS software in order to identify critical areas.

The system is based on the interaction of the different layers. In a first step it generates its own risk map for the area and subsequently it identifies a portion of it according to the structural capacity of the archaeological asset to withstand any dangers (floods, etc.).

The developed methodology involves the risk calculation through the combination of the components of each individual layer, related to the position of point of interest. So, the risk function involve some parameters that characterize the conservation status of individual point of interest and other parameters that describe deterioration system.

The parameters define effects level suffered by the asset due to its exposure to aggression of degradation agents and the degree of potential aggression characteristic of a given territorial area. Based on the available data, when updating them, through the calculation procedures, we can know the level of Territorial Danger, the Vulnerability Index of the individual asset and the intensity of Risk and represent the corresponding spatial distributions. 
In Cultural Heritage geodatabase, a table (descriptive form) with a matched value (index of intervention priority) is associated to each entity.

Data about asset are mainly related to:

- Structure attributes (year of construction, type of construction, materials used, dimensions ..)

- historical and artistic importance

- economic capacity of attractiveness

Information about assets was acquired using various geomatics techniques.

There are many tools and technologies that allow to analyse, catalogue and monitor Cultural Heritage, starting from the Laser Scanner [23-25] to close range photogrammetry [26-27], tools that can also be applied to underwater heritage [28-29].

An example of Point of Interest table (descriptive form) is given in Fig. 9.

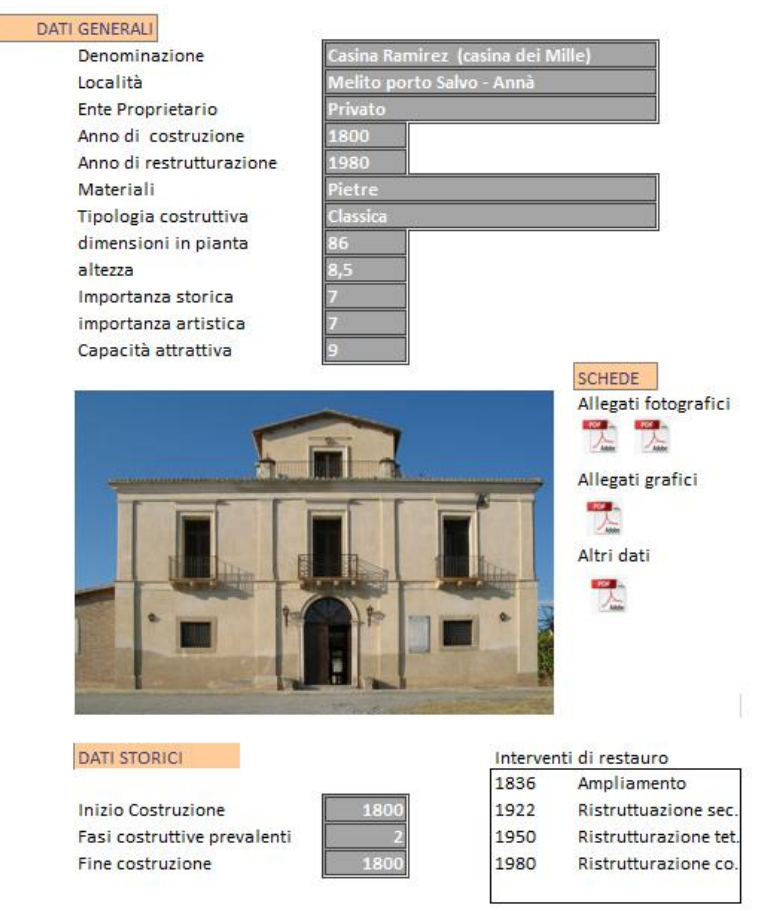

Fig.9 Ramirez House example form.

A value describing importance and attractiveness is associated to each asset.

All raster and vector layers are related and processed through a metaheuristic analysis aimed to identify areas that need maintenance activities and general risk areas.

Thereafter, metaheuristic analysis combines data of all layers for each asset and provide a value that interacts with geometric parameters (distance from the centre, distance from roads, economic parameters of attractiveness). These parameters are characteristic of the point of interest, obtaining a further intervention priority value. This value obtained is therefore associated with a represented area.

Principal steps of metaheuristic analysis are described in Fig. 10:

- Cultural Heritage Inventory mapping: relationships between assets of interest and historical centres are defined. The choice of factors characterizing the area and therefore the asset under investigation is the level necessary to identify the various parameters that define the state of risk or need for intervention of an area.

- Importance analysis: all parameters are related to each other.

- Cultural Heritage susceptibility mapping using FR model: Frequency Ratio model is used to define probabilistic relationships between dependent and independent variables, including multi-classified maps.

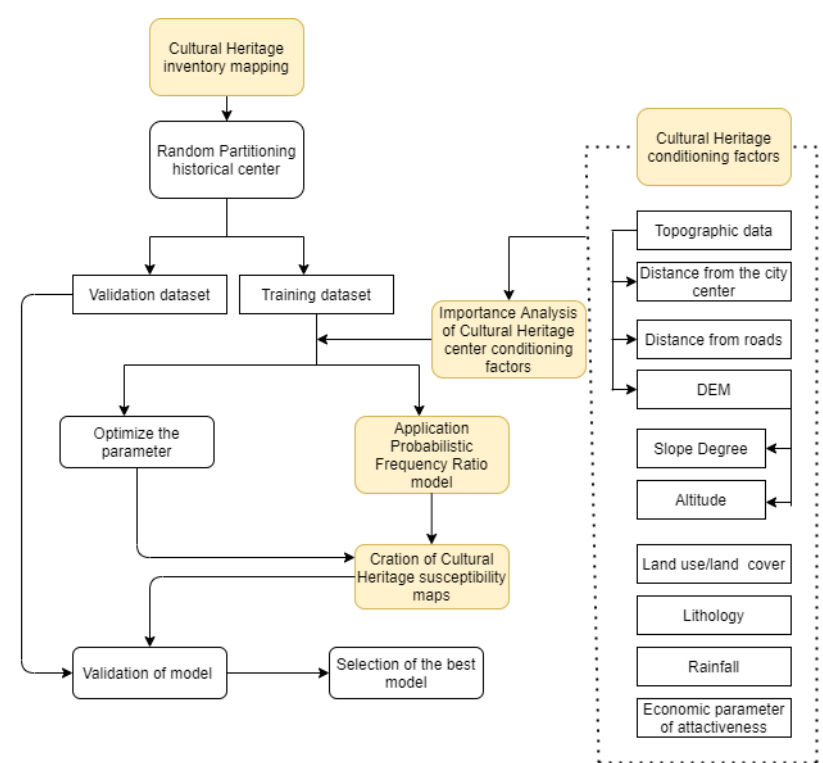

Fig.10 Metaheuristic analysis: Flowchart.

All pixels having this value are aggregated and exported as vectorial format to generate a spatial map of the cultural heritage and the place with priority need of restoration (Fig. 11).

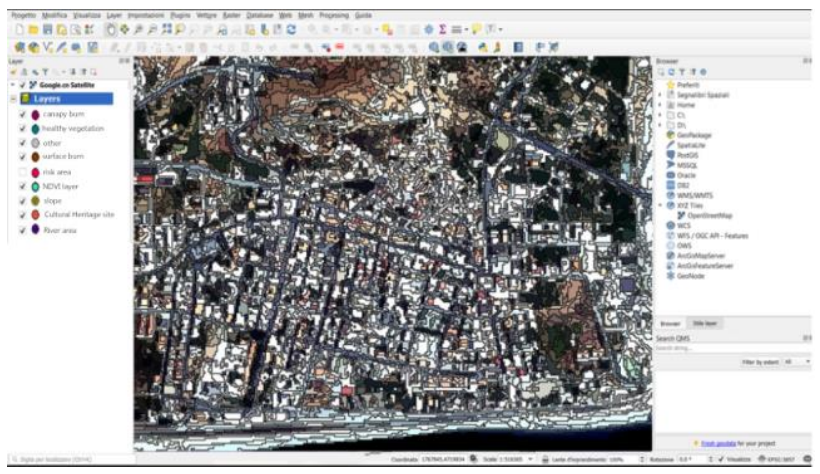


Fig.11 GIS elaboration historical centre with risk areas.

By way of example, the following figures show the results of the analyzes obtained in the first and last year.

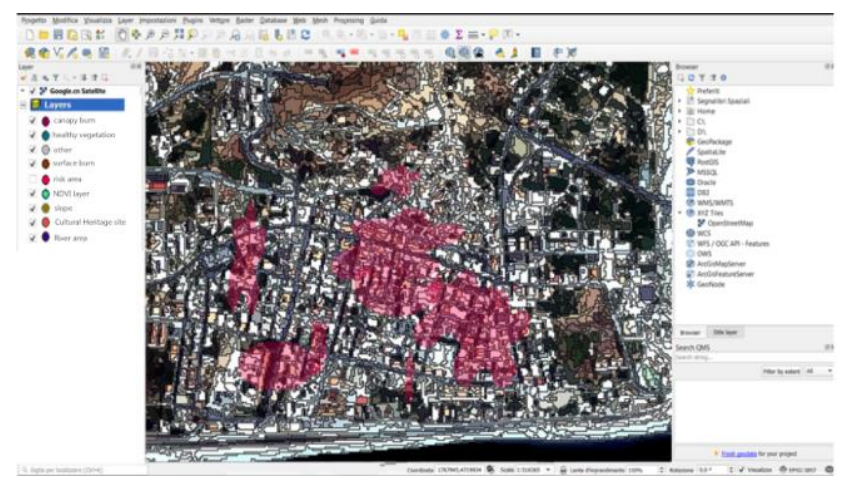

Fig.12 GIS with identification of initial hazard areas.

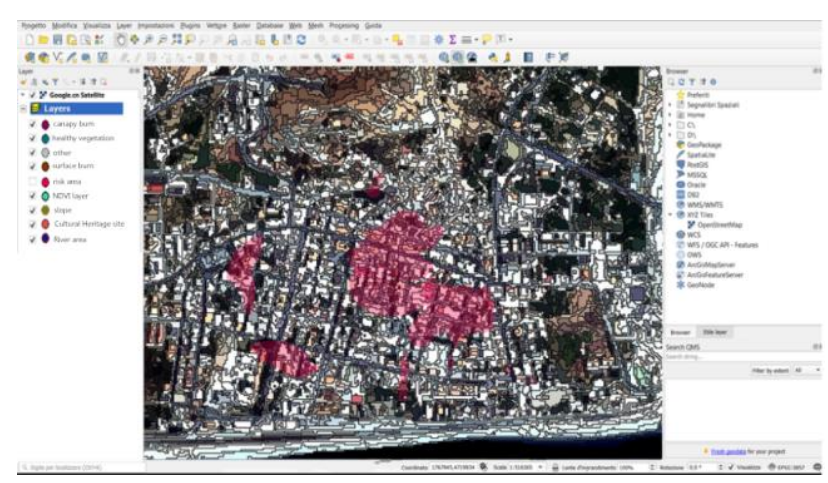

Fig.13 GIS with identification of final hazard areas.

\section{Results}

Figures 12 shows the processing for the identification of hazard of the whole area as a function of all the risk parameters. Subsequently these parameters have been integrated with parameters about Cultural Heritage and with metaheuristic analysis (Fig. 13).

Studies based on OBIA have well proven to be useful in evaluations also with regard to archaeological heritage and landscape archeology [30-33] while still other tools for ground investigations are added [34] and new image acquisition platforms such as UAVs add further perspectives to monitoring [35-37], further strengthened by the contribution of Machine Learning [38]. It is not ruled out that the latest advances in image analysis may lead to further results [39-40].
Metaheuristics analysis with GIS tools have been performed and the results showed that historic centre has undergone several transformations that put its integrity at risk.

\section{Conclusions}

Constant monitoring is an essential step to safeguard Cultural Heritage. The continuous availability of satellite images and their analysis techniques, as the OBIA, allow extraction of information in a way that can be easily integrated in a GIS and assume an increasingly relevant importance to monitor regions and historical heritage.

The "inherited" parts of our settlements represent a complex cultural asset and valuable fixed capital of great potential for the quality of contemporary living space.

Compared with other technologies, OBIA allows a good interpretation of the scene captured by the sensor thanks to its segmentation, to the extraction of objects with their topological relations, also in relation to the context. This leads to a classification similar to those of the human photo-interpreter but with a better reproducibility and homogeneity.

The implemented GIS is useful for management of geographic information related to other information on the territory. Metaheuristic analysis performed with GIS play an important role for study historic centres, manage and conservation optimize of Cultural Heritage. With GIS is possible to generate spatial maps about cultural heritage and classify points of archaeological interest. Therefore, users are able to identify the places that with priority need restoration and to obtain information about changes occurred over time. Moreover, GIS is useful for all the citizens for disseminating geographic and spatial information, and managing cartographic research.

Future work could be focused on improving the performance of the system through the deepening of metaheuristic analysis, considering also for OBIA the contribution of UAV images that can integrate, as a source of data easily usable, the analysis of satellite data to be acquired at regular intervals. The idea is to provide for the acquisition of highresolution satellite data at regular intervals, so as to have a regular time scan, and at the same time organize the zenithal acquisitions from drone, so that in the Points of Interest there are also comparable data at very high resolution. 


\section{Acknowledgements}

Thanks to the European Space Agency for having purchased and made available satellite imagery, and software for the related processing, during the internship carried out at the Italian ESA headquarters in Frascati, Rome.

\section{References:}

[1] ISTAT, Musei ed istituzioni similari, 2016. Retrieved from http://dati.istat.it/Index.aspx?DataSetCode=DC IS MUSVIS

[2] Eichberg M., Contribution in: Salvaguardare $i$ centri storici, Finestre sull'arte, Vol.5, 2020, pp. 29-30.

[3] Salzano E., Diciamo NO al progetto di legge urbanistica della regione Emilia Romagna!. 2017 , Retrieved from https://www.eddyburg.it/2017/01/diciamo-noal-progetto-di-legge.html

[4] De Lucia V., Contribution in: Salvaguardare $i$ centri storici, Finestre sull'arte, Vol.5, 2020, pp. 28-29.

[5] Köppen, M., Ruiz-del-Solar, J., Soille, P., Texture Segmentation by biologically-inspired use of Neural Networks and Mathematical Morphology. Proceedings of the International ICSC/IFAC Symposium on Neural Computation (NC'98), ICSC Academic Press, Vienna,1998, pp. 23-25.

[6] Serra, J., Image Analysis and Mathematical Morphology. 2, Theoretical Advances, Academic Press, New York, USA, 1998.

[7] Soille, P., Pesaresi, M., Advances in Mathematical Morphology Applied to Geoscience and Remote Sensing. IEEE Transactions on Geoscience and Remote Sensing, 2002, Vol.40, No.9, 2002, pp. 20422055.

[8] Zadeh L.A., Fuzzy Sets. Information Control, Vol.8, 1965, pp. 338-353.

[9] Tzeng Y.C., Chen, K.S., A Fuzzy Neural Network to SAR Image Classification. IEEE Transaction on Geoscience and Remote Sensing, Vol.36, 1998, pp. 301-307.

[10] Baatz, M., Benz, U., Dehgani, S., Heynen, M., Höltje, A., Hofmann, P., Lingenfelder, I., Mimler, M., Sohlbach, M., Weber, M., Willhauck, G., eCognition 4.0 professional user guide. Definiens Imaging $\mathrm{GmbH}$, München, Germany, 2004.

[11] Bianchin, A., Pesaresi, M., Approccio strutturale all'analisi di immagine per la descrizione del territorio: una esplorazione degli strumenti di morfologia matematica. Atti del V Convegno Nazionale A.I.T., Milano, Italy, 1992, pp. 25-29.

[12] Pesaresi, M., Texture Analysis for Urban Pattern Recognition Using Fine-resolution Panchromatic Satellite Imagery. Geographical \& Environmental Modelling, Vol.4, No.1, 2000, pp. 43-63.

[13] Benediktsson, J.A., Pesaresi, M., Arnason, K. Classification and Feature Extraction for Remote Sensing Images from Urban Areas Based on Morphological Transformations. IEEE Transactions on Geoscience and Remote Sensing, Vol.41, No.9, 2003, pp. 1940-1949.

[14] Bilotta, G., Metodologie avanzate applicate allo studio dell'uso della terra. Carto Graphica, ISSN: 1974-2177, Vol.12, 2005, pp. 21-24.

[15] Barrile, V., Bilotta, G., Metodologie "Strutturali" su immagini Satellitari per l'analisi Urbana e Territoriale. Proceedings XI ASITA, Torino (Italy), 2007, pp. 267-272.

[16] Barrile, V., Bilotta, G., An application of object-oriented analysis to very high resolution satellite data on small cities for change detection. Recent Advances in Electrical Engineering, Proceedings of $3 r d$ WSEAS Conference on Remote Sensing (Remote '07), November 21-23, 2007, Venice, Italy, 2007, pp. 98-103.

[17] Barrile, V., Bilotta, G., An application of Remote Sensing: Object oriented analysis of satellite data. Int. Arch. Photogramm. Remote Sens. Spatial Inf. Sci., Vol. XXXVII, 2008, pp. 107-114.

[18] Barrile, V., Bilotta, G., Meduri, G.M., An application of object-based analysis of satellite imagery on waste. Towards Horizon 2020, Proceedings of 33rd EARSeL Symposium, 3-6 June 2013, Matera, Italy, 2013, pp. 791-798.

[19] Barrile, V., Bilotta, G., Pannuti, F., A Comparison Between Methods - A Specialized Operator, Object Oriented and Pixel Oriented Image Analysis - To Detect Asbestos Coverages in Building Roofs using Remotely Sensed Data. Int. Arch. Photogramm. Remote Sens. Spatial Inf. Sci., Vol. XXXVII, 2008, pp. 427-434.

[20] Barrile, V., Bilotta, G., Fast extraction of roads for emergencies with segmentation of satellite imagery. Procedia: Social\&Behavioral Sciences; Vol.223, 2016, pp. 903-908, doi: 10.1016/j.sbspro.2016.05.313.

[21] Barrile, V., Bilotta, G., Fotia, A., Bernardo, E., Road Extraction for Emergencies from Satellite 
Imagery. Lecture Notes in Computer Science, Proceedings of 20th International Conference on Computational Science and Its application (ICCSA 2020), Cagliari, Italy, 2020, pp. 767781.

[22] Barrile, V., Bilotta, G., Fotia, A., Bernardo, E., Integrated GIS System for Post-fire Hazard Assessments with Remote Sensing. Int. Arch. Photogramm. Remote Sens. Spatial Inf. Sci., Vol. XLIV, 2020, pp. 13-20, ISSN: 1682-1750, doi: $\quad$ https://doi.org/10.5194/isprs-archivesXLIV-3-W1-2020-13-2020.

[23] Barrile, V., Meduri, G.M., Bilotta, G., Comparison between two methods for monitoring deformation with Laser Scanner. WSEAS Transactions on Signal Processing, 2014, Vol.10, No.1, pp. 497-503.

[24] Barrile, V., Meduri, G.M., Bilotta, G., Experimentations and integrated applications laser scanner/GPS for automated surveys WSEAS Transactions on Signal Processing, 2014, Vol.10, No.1, pp. 471-480.

[25] Barrile, V., Meduri, G., Bilotta, G., Laser scanner surveying techniques aiming to the study and the spreading of recent architectural structures. Proceedings of the 9th WSEAS International Conference on Signal, Speech and Image Processing, SSIP '09, Proc. 9th WSEAS Int. Conf. Multimedia, Internet and Video Technologies, MIV, 2009, pp. 92-95.

[26] Barrile, V., Bilotta, G., D’Amore, E., Meduri, G.M., Trovato, S., Structural modeling of a historic castle using close range photogrammetry, International Journal of Mathematics and Computers in Simulation, Vol.10, 2016, pp. 370-380.

[27] Barrile, V., Candela, G., Fotia, A., Bernardo, E., UAV Survey of Bridges and Viaduct: Workflow and Application, Lecture Notes in Computer Science (including subseries Lecture Notes in Artificial Intelligence and Lecture Notes in Bioinformatics), Vol.11622 LNCS, 2019, pp. 269-284.

[28] Barrile, V., Fotia, A., Bernardo, E., The Submerged Heritage: A Virtual Journey In Our Seabed, ISPRS Annals of the Photogrammetry, Remote Sensing and Spatial Information Sciences, Vol.42 (2/W10), 2019, pp. 17-24.

[29] Ventura D.; Bonifazi A.; Gravina M.F., Belluscio A., Ardizzone G., Mapping and Classification of Ecologically Sensitive Marine Habitats Using Unmanned Aerial Vehicle (UAV) Imagery and Object-Based Image Analysis (OBIA), Remote Sens. 2018, Vol.10,
No.9, pp. 1331, 2018, doi: $10.3390 /$ rs 10091331.

[30] Meyer M.F., Pfeffer I., Jürgens C., Automated Detection of Field Monuments in Digital Terrain Models of Westphalia Using OBIA, Geosciences, Vol.9, No.3, 2019, p. 109, https://doi.org/10.3390/geosciences9030109.

[31] Davis D.S., Object-based image analysis: a review of developments and future directions of automated feature detection in landscape archaeology. Archaeological Prospection, Vol. 26, No. 2 pp. 155-163, 2019, https://doi.org/10.1002/arp.1730.

[32] Davis D. S., Lipo C. P., Sanger M. C., A comparison of automated object extraction methods for mound and shell-ring identification in coastal South Carolina, Journal of Archaeological Science: Reports, Vol. 23, 2019, pp. 166-177, ISSN 2352-409X, https://doi.org/10.1016/j.jasrep.2018.10.035.

[33] Davis D.S., Object-based image analysis: a review of developments and future directions of automated feature detection in landscape archaeology. Archaeological Prospection, Vol. 26, No. 2, pp. 155-163, 2019, https://doi.org/10.1002/arp.1730.

[34] Tapete D., Earth Observation, Remote Sensing, and Geoscientific Ground Investigations for Archaeological and Heritage Research, Geosciences, Vol.9, No.4, pp. 161, 2019, https://doi.org/10.3390/geosciences9040161.

[35] Liu C., Cao Y, Yang C, Zhou Y, Ai M., Pattern identification and analysis for the traditional village using low altitude UAV-borne remote sensing: multifeatured geospatial data to support rural landscape investigation, documentation and management, Journal of Cultural Heritage, Vol. 44, pp. 185-195, 2020, ISSN 1296-2074, https://doi.org/10.1016/i.culher.2019.12.013.

[36] Sărășan A., Ardelean A, C., Bălărie A., Wehrheim R., Tabaldiev K., Akmatov K., Mapping burial mounds based on UAV-derived data in the Suusamyr Plateau, Kyrgyzstan, Journal of Archaeological Science, Vol. 123, 2020, 105251, ISSN 0305-4403, https://doi.org/10.1016/j.jas.2020.105251,

[37] Davis D. S., Seeber K. E., Sanger M. C., Addressing the problem of disappearing cultural landscapes in archaeological research using multi-scalar survey, The Journal of Island and Coastal Archaeology, 2020, DOI: 10.1080/15564894.2020.1803457.

[38] Maltezos E., Protopapadakis E., Doulamis N., Doulamis A., Ioannidis C. Understanding 
Historical Cityscapes from Aerial Imagery Through Machine Learning. In: Ioannides M. et al. (eds) Digital Heritage. Progress in Cultural Heritage: Documentation, Preservation, and Protection, EuroMed, Lecture Notes in Computer Science, Springer, Cham, Vol. 11196, 2018, doi: 10.1007/978-3-030-01762$0 \quad 17$.

[39] Sergey Á. Stankevich, Mikhail Á. Popov, Sergiy V. Shklyar, Konstantin Y. Sukhanov, Artem Á. Andreiev, Artur R. Lysenko, Xing Kun, Cao Shixiang, Shi Yupa, Zhang Xing, Sun Boya, Subpixel-shifted Satellite Images Superresolution: Software Implementation, WSEAS Transactions on Computers, ISSN / EISSN: 1109-2750 / 2224-2872, Vol. 19, 2020, Art. \#5, pp. 31-37.

[40] Archana O. Vyas, Sanjay V. Dudul, Hybrid DWT- DCT Image Steganography for Encrypted Secret Image, WSEAS Transactions on Information Science and Applications, ISSN / E-ISSN: 1790-0832 / 2224-3402, Vol. 16, 2019, Art. \#5, pp. 49-56.

\section{Creative Commons Attribution \\ License 4.0 (Attribution 4.0 \\ International , CC BY 4.0)}

This article is published under the terms of the Creative Commons Attribution License 4.0

https://creativecommons.org/licenses/by/4.0/deed.en US 